\title{
Métricas da Química Verde - A Produtividade Atómica
}

\author{
Adélio A. S. C. Machado*
}

A complexidade da Química Verde exige variadas métricas para avaliar o elusivo conceito de verdura (as características da quimica que suportam o Desenvolvimento Sustentável), que são fundamentalmente de dois tipos: (i) Métricas de massa e (ii) Métricas ambientais. $O$ artigo, após vincar as dificuldades da aferição da verdura, visa a apresentação e discussão das métricas mais importantes do primeiro tipo. As métricas clássicas da Quimica Industrial (Métrica económica, Rendimento e Selectividade) não são informativas quanto ao desperdicio de átomos dos reagentes em resíduos - ou quanto à utilização eficaz desses átomos no produto desejado, prescrita pelos dois primeiros Princípios da Química Verde (Prevenção e Economia atómica). A eficácia da utilização dos átomos é traduzida pela Produtividade atómica, um conceito complexo que exige novas métricas de massa com dois objectivos: (i) incentivar a incorporação de átomos no produto - Utilização atómica e Economia atómica; e (ii) minimizar a produção de resíduos - Factor $\mathrm{E}$ e Intensidade de Massa. Aborda-se a génese e natureza destas métricas de massa, as relações entre elas e as dificuldades do seu cálculo ao longo do desenvolvimento do processo químico.

Quando se vai ao supermercado comprar uma alface, verifica-se que não esteja amarelecida antes de se concretizar a aquisição - avalia-se a frescura das diversas plantas à venda pelo grau de verdura que mostram. Semelhantemente, em Química Verde $(Q V)$, é fundamental avaliar até que ponto as reacções químicas de síntese, os processos do seu fabrico industrial, os próprios produtos e os usos que se lhes dá, etc., são, de facto, verdes - por isso, presentemente, a química tem o novo problema de lidar com a verdura química, um conceito complexo e difícil de definir, mas que tem a ver com a extensão em que as características da química praticada suportam o Desenvolvimento Sustentável [1].

Este artigo tem como finalidade global divulgar o novel conceito de verdura química por meio da sua discussão, envolvendo quatro objectivos concretos. Primeiro, discutir brevemente as causas da complexidade da verdura da QV e das dificuldades da sua avaliação, e evidenciar a necessidade do desenvolvimento de ferramentas próprias para a realização desta métricas $^{1}$ de tipos mais variados do que as usadas para medir a eficácia da química tradicional. Segundo, evidenciar as limitações das métricas

\footnotetext{
LAQUIPAI, Departamento de Química da Faculdade de Ciências da Universidade do Porto, R. Campo Alegre, 687, 4169-007 Porto $687,4169-007$ Porto
}

clássicas da química para aferir a eficiência global da manipulação e aproveitamento dos átomos nas reacções químicas. Terceiro, mostrar como os dois Primeiros Princípios da QV [2], respectivamente o Princípio da Prevenção de Resíduos e o Princípio da Economia Atómica [1], que, como todos os restantes Doze Princípios da $Q V$, são prescrições de natureza qualitativa, dão origem ao conceito de produtividade atómica [3] quando se procede à sua quantificação. Quarto, apresentar as métricas mais simples e intuitivas usadas para aferir esta nova produtividade e discutir as suas características.

\section{As DIFICULDADES DE AVALIAÇÃo DA VERDURA QUÍMICA}

A avaliação da verdura em QV é substancialmente mais difícil do que a das alfaces, porque a verdura da química é muito complexa, para o que contribuem diversas causas (ver Quadro 1). Em primeiro lugar, porque o conceito tem um alcance vasto e diversificado - aplica-se aos compostos, à sua utilização, aos processos para o seu fabrico industrial, etc. Depois, porque a verdura engloba diferentes facetas de benignidade ambiental, quer dos compostos quer dos processos de fabrico. Em ambos os casos, a verdura é determinada por um agregado de características variadas que permitam a Sustentabilidade, isto é, que impli- quem, por exemplo, que o composto ou processo (i) seja intrinsecamente benigno - não tenha efeitos nocivos para os humanos, a biosfera e o ambiente; (ii) aproveite bem os átomos dos reagentes e não dê origem a muitos resíduos, particularmente se tóxicos e perigosos; (iii) envolva/possa ser preparado por reacções suaves e que não consumam muito energia; (iv) use reagentes obtidos a partir de matérias-primas renováveis, etc. Em terceiro lugar, porque a Química Industrial é ela própria um sistema complexo, que envolve um número muito elevado de produtos químicos diversificados (muitas dezenas de milhar) e variados processos de fabrico (alguns milhares).

Esta situação implica que, para se avaliar a verdura dos produtos químicos, reacções e processos industriais de fabrico, modos de utilização, etc., se tenha de usar uma variedade de métricas. Estas podem agrupar-se em dois tipos: (i) métricas destinadas a aferir a verdura química intrínseca das reacções em termos do cumprimento dos princípios programáticos da $Q V$, os dois primeiros dos seus Doze Princípios - as métricas de massa (justificação deste nome adiante); e (ii) métricas de avaliação da benignidade ambiental das reacções e compostos, que resultam dos restantes princípios, de natureza operacional - as métricas ambientais, nome em que o adjectivo tem sentido lato. 
Estas últimas [4,5], que não serão tratadas neste artigo, têm como objectivo genérico avaliar os impactos ambientais dos produtos químicos e dos processos do seu fabrico, para evitar a utilização de substâncias tóxicas e/ ou perigosas, diminuir os efeitos da Indústria Química sobre o ambiente, etc. - visam obter a verdura ambiental. Como há bastantes parâmetros a aferir, o número de métricas de ambos os tipos exigidas pela QV é elevado, a sua definição é frequentemente complexa e a escolha das mais adequadas é subjectiva e sujeita a debate. execução laboratorial, é geralmente simples. A aferição da reacção ao longo do desenvolvimento do processo, quando se vai aumentando a escala, é normalmente realizada várias vezes ao longo do escalamento, cada vez com mais detalhe nos dados usados, pelo que, em geral, a elaboração das métricas vai crescendo.

Finalmente, quando se pretende avaliar um processo industrial já em funcionamento, por exemplo, para investigar a sua verdura e fazer a sua remodelação para aumentar a sua

Quadro 1 A complexidade da verdura em QV

Conceito de amplo alcance- aplica-se a:
Reacções de síntese
Processos de fabrico industrial
Produtos químicos
Usos dos produtos, etc.
Conteúdo de características variadas dirigidas à Sustentabilidade ambiental
Benignidade intrínseca dos produtos
Sem toxicidade
Sem perigosidade física, etc.
Benignidade da preparação dos produtos
Sem produção de resíduos
Por reacções suaves
Sem consumir muita energia
Fabricados a partir de matérias-primas renováveis, etc.
Química Industrial é um sistema de grande complexidade
Número muito elevado de produtos químicos variados
Processos industriais numerosos e diversificados
Variadas operaç̃es unitárias e processos químicos
Tecnologias muito diversificadas
Escalas de produção muito elevadas, etc.
Muitos parâmetros a aferir
Número de métricas elevado
Definição de métricas complexa
Escolha subjectiva e sujeita a debate

Por outro lado, as métricas da QV são usadas em situações diversas, de diferente complexidade, ao longo do escalamento das reacções desde o laboratório até à instalação industrial, o que implica o uso de diferentes processos de cálculo (e até de métricas distintas). Mais precisamente, quando se considera o cálculo de métricas de massa, a aferição de várias reacções alternativas de síntese num estudo preliminar, feito com base em dados de literatura referentes à sua benignidade ambiental, deve-se usar, tanto quanto possível, dados reais do processo - mas podem não estar disponíveis todos os requeridos, pelo que se têm de fazer hipóteses quanto aos inacessíveis, o que torna os cálculos mais complexos (e pode até incentivar o uso de várias métricas alternativas em simultâneo).

Um outro aspecto a ter em conta é que, em face da complexidade das situações encontradas na Química In- dustrial, e dada a natureza intrínseca do conceito de métrica na avaliação de sistemas complexos, que envolve incertezas elevadas, não se pode esperar que, em geral, as métricas da QV forneçam avaliações de valor absoluto sobre produtos e processos. Por isso, normalmente, os cálculos das métricas são feitos para diversas alternativas viáveis de produtos, processos, etc., que possam competir eficazmente entre si, e têm em vista compará-las para seleccionar a meIhor.

Por estas razões, a definição e implementação das métricas constitui presentemente um campo de investigação de grande actualidade e importância da QV.

\section{As LIMITAÇõES DAS MÉTRICAS CLÁSSICAS DA QUÍMICA}

A avaliação das reacções químicas em Química Académica ou Laboratorial usa como métrica de eficiência de manipulação dos átomos, quase exclusivamente, o rendimento químico do produto desejado. Quando os reagentes podem reagir segundo várias reacções paralelas e originar simultaneamente vários produtos, obter um rendimento elevado exige selectividade elevada, pelo que, particularmente em Química Industrial, esta outra métrica de eficiência é também importante. O rendimento é um conceito muito usado em Química Laboratorial, mas a selectividade é menos - em geral, só surge em cadeiras especializadas sobre catálise; por isso, aborda-se a seguir este conceito, em particular a sua relação com o rendimento, que é relevante para a metrificação da QV.

O rendimento é a grandeza classicamente utilizada pelos químicos para exprimir a eficiência com que conseguem realizar as reacções químicas de síntese para obter compostos - é a razão, em geral expressa em percentagem, entre a quantidade de produto obtido no processo de síntese e a quantidade teoricamente esperada a partir da estequiometria da reacção, se todo o reagente limitante 
originasse produto. $\mathrm{O}$ rendimento assim definido é aplicável aos processos de carga (ou partida), vulgarmente utilizados pelos químicos no laboratório e pelos químicos industriais que realizam Química Fina. Neste tipo de processo, carrega-se o vaso de reacção, deixa-se ocorrer a reacção e, no fim, descarrega-se a mistura obtida e, se for caso disso, isola-se e purifica-se o produto. O rendimento pode ser calculado a partir das massas de reagentes usados e de produto obtido, por meio das massas moleculares e da equação química que traduz a reacção, devidamente acertada. ${ }^{2}$

A selectividade é uma grandeza intimamente relacionada com o rendimento. Diz respeito à situação em que um mesmo conjunto de reagentes pode dar origem a uma série de produtos diferentes por reacções paralelas - neste caso, o produto desejado é acompanhado por coprodutos (ver a Fig. 1). ${ }^{3}$

A selectividade é a razão entre a quantidade de produto obtido e a quantidade teoricamente esperada a partir da estequiometria da reacção se todo o reagente limitante que foi convertido (exclui-se o que não reagiu!) originasse só o produto, sem produzir paralelamente coprodutos. Tal como o rendimento, é vulgarmente expressa como percentagem, mas calculada com base na razão da quantidade de reagente convertido no produto desejado para a quantidade total de reagente convertido em produto e coprodutos. Quanto maior for a selectividade, maior é a quantidade do produto relativamente à dos coprodutos, isto é, idealmente, maior é o rendimento. Por isso, em Química Industrial, procura-se desde sempre controlar as condições de reacção, por exemplo, optimizar o catalisador, de modo a obter selectividade elevada - para maximizar o rendimento.

No entanto, na prática real dos processos químicos, a maximização da selectividade pode exigir uma mudança de condições para valores tais que o rendimento diminua - assim, a relação entre as duas grandezas nem sempre é tão simplista como a Fig. 1 sugere.

\section{SELECTIVIDADE E RENDIMENTO}
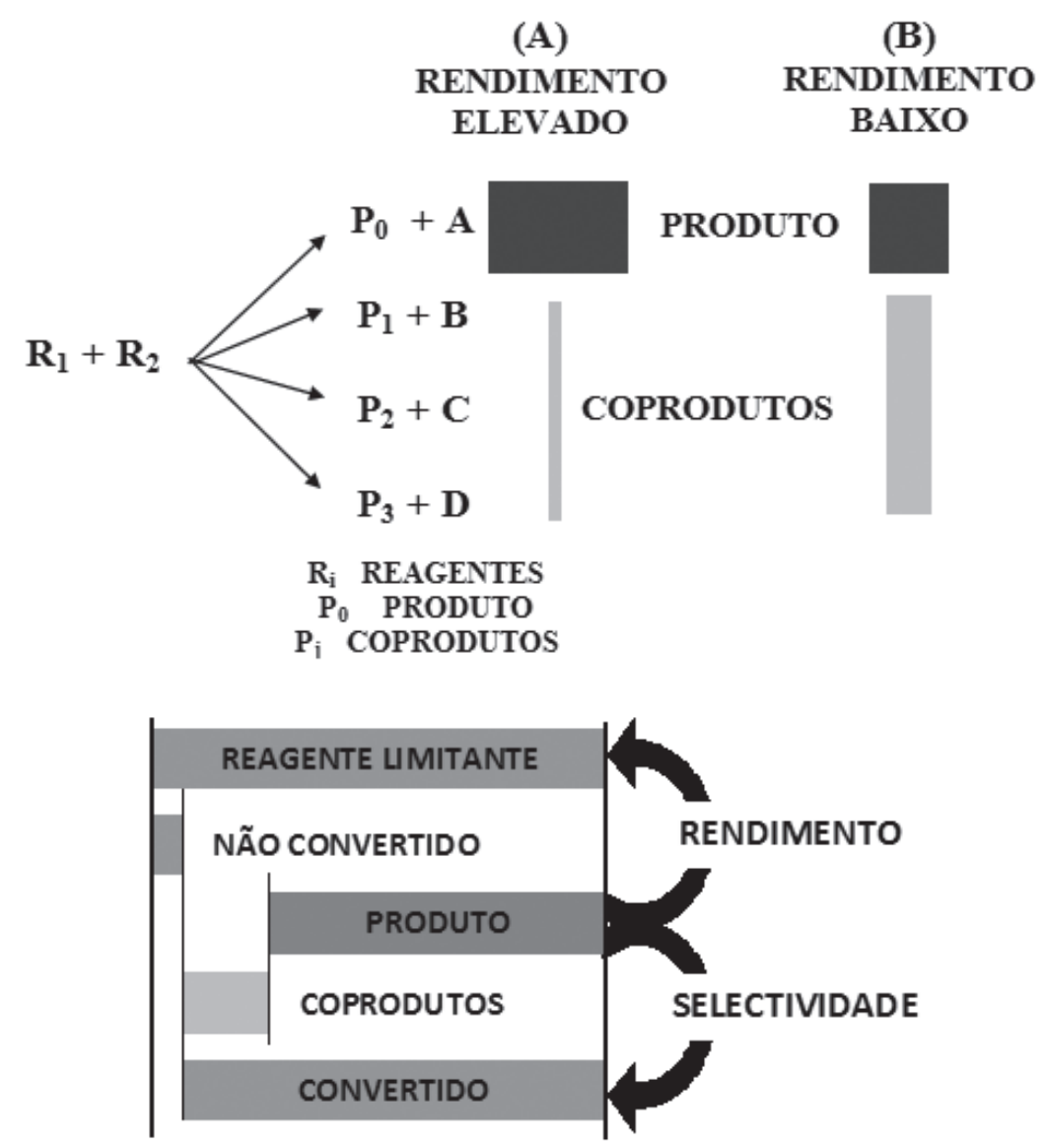

Figura 1 Relação entre a selectividade e o rendimento. As áreas dos rectângulos representam quantidades de compostos. Em cima - Quanto maior for a selectividade maior é o rendimento: (A) a produção do composto desejado pela primeira reacção predomina sobre a produção de resíduos pelas outras reacções e o rendimento é elevado; (B) formam-se mais coprodutos e menos produto desejado e o rendimento é baixo. Em baixo - Destino do reagente limitante e quantidades usadas no cálculo do rendimento e da selectividade; as setas são dirigidas do numerador para o denominador das definições

Além das anteriores, há uma terceira métrica importante em Química Industrial: a chamada métrica económica, que avalia se o produto pode ser preparado e vendido com lucro, com base nos custos dos reagentes e no seu preço presumível de venda.

Em suma, tradicionalmente, o paradigma de avaliação das reacções químicas em Química Industrial envolve três métricas: métrica económica, rendimento e selectividade. As duas últimas são obtidas por cálculos estequiométricos (balanços materiais), pelo que são designadas métricas de massa, e a primeira por um cálculo do mesmo tipo, mas que envolve também o super-elemento $€[6]$ (custos por unidade de massa).

As duas métricas de massa são calculadas tendo em atenção apenas os reagentes estequiométricos, os que surgem nas equações químicas, ignorando todos os restantes (reagentes auxiliares, solventes, catalisadores, etc.), frequentemente usados em maiores quantidades que os primeiros, mas cujos átomos não são incorporados no produto. Em consequência, quando se considera a totalidade dos reagentes, o rendimento e a selectividade não aferem a eficácia global do aproveitamento dos respectivos átomos para a "construção" do produto - por si só, a maximização daquelas grandezas não implica um aumento significativo de eficácia quanto à utilização da totalidade dos átomos em jogo na reacção. Em particular, em Química Orgânica Fina, quando a molécula produto é elaborada e a via de sintese para a sua preparação envolve várias reacções sucessivas, sucede muitas vezes que, para se chegar ao produto final, uma fracção significativa dos átomos dos reagen- 
tes acabam por ser incorporados em resíduos, ${ }^{4}$ e não no produto - esta situação corresponde a uma baixa eficiência global do uso da matéria total manipulada na via de síntese. AQV visa o aumento desta eficiência, mas o rendimento e a selectividade são métricas mudas quanto a esta grandeza - não a aferindo, nada dizem sobre ela. Por isso, a QV requer uma mudança de paradigma de avaliação da eficiência do uso dos átomos nas reacções químicas - com introdução de novas métricas de massa.

As NOVAS MÉTRICAS DE MASSA DA QV - A PRODUtiVIDADE atómica

A quantificação dos Princípios da Prevenção e da Economia Atómica. A utilização eficaz dos (átomos dos) reagentes de modo a incorporá-los na maior extensão possível no produto e a produzir poucos resíduos em paralelo com este, é um objectivo fundamental da $Q V$, que resulta dos dois primeiros Princípios [1,2]. O primeiro (Prevenção) prescreve a prevenção proactiva contra a produção de resíduos, logo desde o início da planificação do processo de fabrico de um produto quími$\mathrm{co}$, a qual tem valor acrescentado sobre a eliminação reactiva, no fim do processo, dos resíduos produzidos ao longo deste (também neste caso, vale a máxima da sabedoria popular: mais vale prevenir que remediar!); o segundo (Economia atómica), recomenda a incorporação maximizada dos átomos dos reagentes no produto. O cumprimento qualitativo do referido objectivo geral da QV passa pela prática continuada destes princípios na realização da química - por exemplo, por escolha de reacções de síntese adequadas, diminuição da utilização de reagentes auxiliares (solventes, etc.) na maior extensão que for possível, etc. - mas a avaliação do respectivo grau de cumprimento requer a sua quantificação. Para esta, são necessárias novas métricas de massa que possam avaliar que fracção dos átomos entrados nos reagentes é integrada no produto ou acaba por ir parar a resíduos - são essenciais para uma prática da química que optimize o conjunto das variáveis em jogo para maximizar a obtenção do produto e, simultaneamente, mini- mizar a produção de resíduos.

O objectivo duplo da QV - Uma mudança de paradigma. No início dos anos noventa do século $\mathrm{XX}$ (ver adiante) reconheceu-se que nas reacções de síntese de compostos era tão importante prestar atenção aos resíduos como ao produto, já que a postura clássica de maximização exclusiva de rendimento químico não garante o uso eficaz dos recursos atómicos aportados nas matérias-primas - descobriu-se que, para usar eficientemente os átomos dos reagentes, era tão fundamental minimizar a produção de resíduos como maximizar o rendimento. ${ }^{5}$ Esta descoberta levou à emersão de uma nova postura dos químicos de processo, a qual é um dos pilares mais fortes da QV - a inclusão da não produção de resíduos como um segundo objectivo tão importante como a obtenção do produto, que deve ser sempre perseguido, proactiva e sistematicamente, com forte voluntarismo. Este objectivo é fácil de afirmar, mas a sua concretização é quase sempre problemática, já que as vias de síntese e as próprias reacções químicas que as constituem são complexas, porque envolvem quebra e formação de numerosas ligações químicas, governadas por múltiplas leis de diversos tipos, e requerem operações físicas auxiliares (separações, purificações, etc.).

Esta mudança explícita de atitude paradigmática, afinal o âmago da QV, levantou um novo problema de optimização das condições de realização das reacções químicas, mais complexo que o clássico - porque envolvia objectivos a duas "dimensões": a da produção do produto desejado e a da não produção de resíduos. Como estas duas coordenadas não são ortogonais, os respectivos percursos para atingir a meta final estão correlacionados entre si, e os químicos tiveram de introduzir novas grandezas para os analisar - grandezas que pudessem manejar adequadamente para optimizar globalmente a realização das reacções com vista a obter consensos razoáveis quanto aos resultados que podem ser atingidos em cada uma das duas coordenadas. Foi neste contexto que surgiram e têm sido investigadas as novas métricas de massa da QV - nomeadamente as discutidas adiante, as mais intuitivas e fáceis de calcular.

Produtividade atómica. No fundo, independentemente das métricas usadas, o que está em jogo na metrificação de massa da QV é um conceito básico mais global, introduzido em 2000 [3] - a produtividade atómica.

Em economia da empresa, a produtividade é um conceito económico muito importante - o seu incremento é uma meta sempre a perseguir na actividade industrial de fabrico de qualquer produto, porque permite aumentar os lucros. A produtividade de cada factor de produção é definida como a razão da quantidade obtida de produto fabricado para a quantidade desse factor usado no fabrico. Assim, a produtividade é uma medida da eficiência de utilização dos factores de produção, por exemplo, a muito falada produtividade do trabalho, vulgarmente conhecida apenas por produtividade, mede a eficiência de utilização da mão-de-obra.

Nos processos que envolvem transformações de materiais, a produtividade dos materiais é também fundamental mede a eficiência da incorporação das matérias-primas no produto fabricado. ${ }^{6}$ No caso dos processos de síntese realizados pela Indústria Química, a produtividade dos materiais é a chamada produtividade atómica [3] - grandeza que traduz a incorporação dos átomos dos reagentes no produto sem desperdícios em resíduos (Fig. 2).

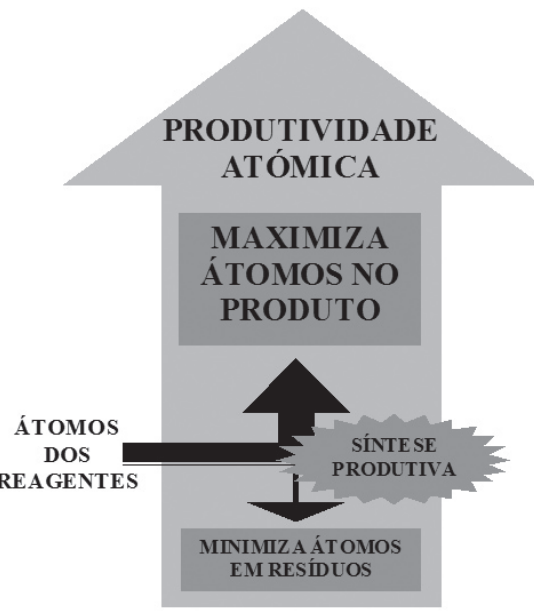

Figura 2 Produtividade atómica. Uma síntese com produtividade atómica elevada coloca os átomos dos reagentes no produto e evita simultaneamente a sua perda em resíduos 
$\mathrm{Na}$ prática, dada a complexidade das vias de síntese, a produtividade atómica é uma grandeza difícil de expressar, mas as métricas discutidas a seguir, que foram sendo introduzidas na QV antes de ter emergido o conceito, têm como objectivo fundamental ajudar à optimização das reacções e processos de síntese de modo a maximizar a produtividade atómica são, no fundo, métricas desta grandeza. Esta fundamentação das métricas de massa no conceito económico de produtividade é interessante porque comprova a existência de uma componente económica na QV, importante para a tornar atractiva para os empresários da Indústria Química - que, como todos os outros, estão sempre interessados em aumentar a produtividade, seja de que tipo for.

As métricas de produtividade atómica. $\mathrm{O}$ conceito de produtividade atómica é complexo e as suas métricas consideram separadamente 0 que sucede aos átomos nas reacções químicas quando passam dos reagentes para o produto final ou para resíduos, sendo por isso de dois tipos (Fig. 3): (i) incorporação dos átomos dos reagentes no produto; e (ii) minimização da produção de resíduos.

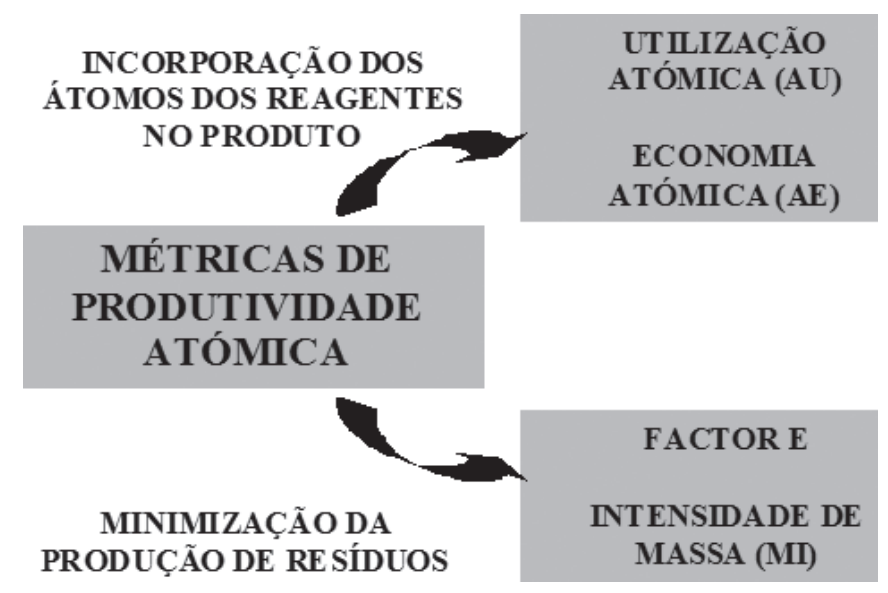

Figura 3 Objectivos das métricas de massa da QV. As métricas avaliam ou a incorporação dos átomos aportados pelos reagentes no produto ou a minimização da produção de resíduos

MÉtricas de INCORPORAÇÃo de ÁTOMOS DOS REAGENTES NO PRODUTO

Começa-se por abordar a filosofia básica do problema de optimizar a utilização dos átomos numa reacção de síntese, discutindo-se depois duas métricas para a sua avaliação: a utilização atómica percentual (AU, de "atomic utilization") e a economia

atómica percentual (AE, de "atomic economy").

A filosofia de base da economia atómica. A ideia básica de economia atómica foi introduzida de forma qualitativa por Trost, em 1991 [7], que descobriu a importância de aumentar a fracção de átomos de reagentes que são englobados no produto final desejado para se obter eficácia nos processos de síntese: "estimular" uma boa economia de utilização dos átomos (no sentido trivial de economia - não desperdiçar átomos, isto é, aumentar a produtividade da sua utilização) é tão importante como conseguir obter rendimento global elevado para se obter eficiência numa síntese. Por isso, tem de se prestar atenção ao destino dos átomos introduzidos no processo pelos reagentes: quanto maior é a fracção destes englobada no produto relativamente à perdida em reagentes, maior será a economia atómica - mais eficaz será a utilização dos átomos (este raciocínio é simplista: admite que não há perdas de átomos por outros processos - fugas, etc.).

A solução ideal para maximizar a economia atómica seria introduzir todos os átomos dos reagentes no produto 
ideal de o produto incorporar todos os átomos dos reagentes (produto formado sem coprodutos, com rendimento de $100 \%$ ), estas métricas atingiriam o valor ideal de $100 \%$; na prática, são sempre inferiores.

A Fig. 4 resume diagramaticamente as definições das duas métricas apresentadas e mostra as suas diferenças. As setas a negro indicam a relação entre as grandezas usadas nas definições das métricas, representadas pelas áreas dos rectângulos; as setas verticais a envolver as definições, com sentido para cima, indicam que as métricas devem aumentar quando se persegue o aumento da verdura. Os valores numéricos $(100 \%)$ para que apontam estas últimas setas são os valores ideais das métricas - funcionam como alvos teóricos a atingir na luta pela verdura.

A partir da equação estequiométrica de uma reacção química, admitindo diversas alternativas de reacções, vias ou processos de síntese, aquando de avaliações preliminares, embora o valor real da métrica seja sempre inferior ao teórico. Pode-se fazer um cálculo do mesmo tipo para a utilização atómica percentual, mas não é usado, porque, já que se ignoram perdas, conduz ao mesmo valor. Na prática, os valores calculados com base em dados experimentais diferem - a economia atómica é inferior à utilização atómica (comparar as áreas na Fig. 4). No entanto, são ambas métricas directas de verdura, a maximizar na perseguição desta.

\section{Métricas de MinimizaçÃo da PRODUÇÃO DE RESÍDUOS}

Para avaliar a extensão da formação de resíduos usam-se outras duas métricas: o Factor $E$ (de "Environmental factor") e a intensidade de massa (MI, de "mass intensity").

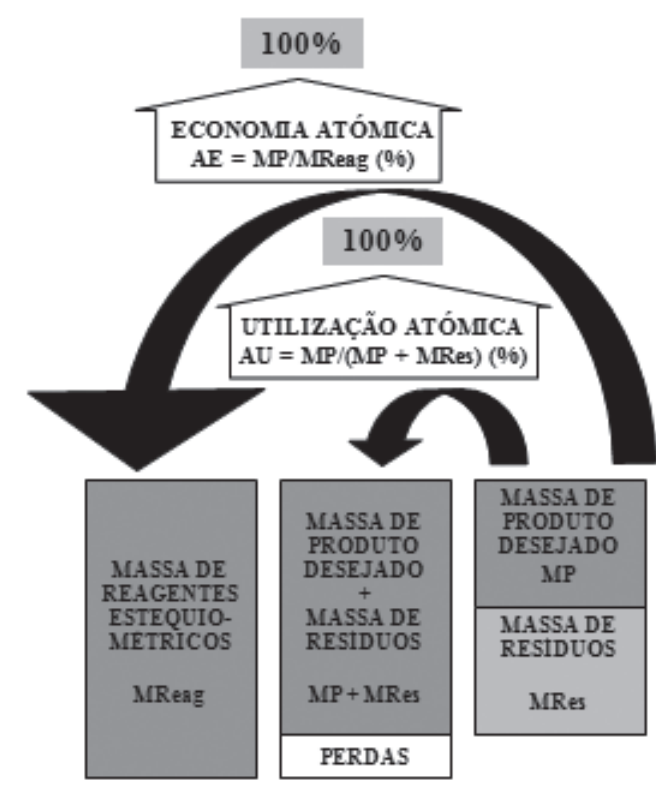

Figura 4 Comparação das definições de utilização atómica percentual (AU)

e economia atómica percentual (AE). Os rectângulos escuros representam as massas usadas nas definições das métricas, sendo as setas curvas dirigidas do numerador para o denominador des tas. Como o que está em jogo é a incorporação dos átomos de reagentes nos produtos, a massa de reagentes não inclui reagentes auxiliares, solventes, etc., mas apenas os reagentes es tequiométricos (comparar com a Fig. 5). As setas que cercam os nomes das métricas, dirigidas para cima, indicam que estas são métricas directas da verdura, dirigidas aos valores ideais indicados

rendimento de reacção igual a $100 \%$, pode-se calcular facilmente o valor teórico da economia atómica percentual, que pode ser usado como primeira aproximação ao valor da métrica. Estes cálculos são muito úteis para aferir a verdura relativa a esperar de
Ambas são métricas directas da quantidade de resíduos formados são tanto maiores quanto maior for esta. Por isso, ao contrário das anteriores, são métricas inversas da verdura do processo - a optimização desta exige a sua minimização.
Factor E. O Factor E é definido como a razão de massas entre a totalidade da massa dos resíduos produzidos e a massa de produto desejado. $\mathrm{O}$ valor ideal do Factor E é zero, que ocorreria se não houvesse produção de quaisquer resíduos; nas situações reais, o Factor $\mathrm{E}$ é frequentemente um número superior à unidade - muitas vezes tem um valor bastante elevado: produzem-se muitos mais resíduos do que produto!

O Factor E, introduzido por Sheldon a par da utilização atómica $[8,9]$, é útil porque põe em evidência a extensão do problema da produção de resíduos no fabrico de substâncias químicas. Em particular, evidencia que este problema tem uma extensão relativa muito diferente nos diversos segmentos da Indústria Química. Na Tabela 1 [8], apresentam-se gamas de valores típicos do Factor E para diversos tipos de indústria: (i) Refinação de petróleo processa grandes massas de materiais mas não produz, em termos relativos, grandes massas de resíduos ( $E$ muito baixo); (ii) Indústria Química Pesada - produz grandes quantidades dos compostos mais utilizados pela indústria química e pelas outras indústrias (ácidos, compostos orgânicos de base, etc), com produção de quantidades relativamente pequenas de resíduos $(E$ baixo: uma fracção substancial dos átomos dos reagentes são incorporados nos produtos); (iii) Indústria Química Fina - produz substâncias mais complexas e caras, em quantidades menores, mas em cuja produção a quantidade de resíduos é relativamente maior $(E$ elevado); e, dentro desta última, a (iv) Indústria Farmacêutica - a produção do produto é frequentemente acompanhada pela acumulação de quantidades relativamente grandes de resíduos ( $E$ muito elevado - a maior parte dos átomos dos reagentes "perdem-se" nos resíduos).

\begin{tabular}{|l|c|c|}
\hline \multicolumn{2}{|c|}{ Tabela 1 O Factor E na Indústria Química [8] } \\
\hline Tipo de indústria & $\begin{array}{c}\text { Produção } \\
\text { (ton/ano) }\end{array}$ & $\begin{array}{c}\text { Factor E } \\
\text { (Massa de } \\
\text { resíduos/ } \\
\text { Massa } \\
\text { de produto) }\end{array}$ \\
\hline Refinação do petróleo & $10^{6}-10^{8}$ & $<0,1$ \\
\hline Química Pesada & $10^{4}-10^{6}$ & $<1-5$ \\
\hline Química Fina & $10^{2}-10^{4}$ & $5-50$ \\
\hline Farmacêutica & $10^{1}-10^{3}$ & $25-100$ \\
\hline
\end{tabular}

Estas diferenças resultam de os processos químicos que envolvem grandes quantidades de matéria (In- 
dústria Química Pesada) serem, em geral, realizados em reactores de fluxo, com catalisadores, e consistirem de uma única reacção ou um número muito limitado de reacções e operações (passos/etapas), em que todos ou quase todos os átomos dos reagentes são incorporados no produto; ao passo que a Indústria Química Fina é quase sempre praticada em reactores de carga e os respectivos processos de síntese envolvem frequentemente um grande número de passos sucessivos, cuja maioria utiliza grandes quantidades de solventes, etc. e, consequentemente, produzem muitos resíduos.

Admitindo que os reagentes são usados em quantidades estequiométricas e os rendimentos são de $100 \%$, pode-se calcular um valor teórico da Factor E pela estequiometria das reacções, a partir das massas moleculares das substâncias que intervêm na reacção, usando a equação química (os reagentes auxiliares, solventes, etc., são contabilizados como resíduos), que, no entanto, não tem grande significado. Na prática, o valor real do Factor E é sempre superior ao teórico, mas o seu cálculo a partir da definição é frequentemente difícil, porque é impossivel identificar completamente os coprodutos e resíduos, estabelecer as suas relações estequiométricas com os reagentes, medir as suas quantidades, etc.

Intensidade de massa (MI). Em face destas dificuldades, e como normalmente se tem informação mais completa sobre os reagentes e outros materiais usados no processo (por exemplo, solventes), bem como sobre o produto obtido, em vez do Factor E podem-se usar outras grandezas alternativas a este. A mais intuitiva e vulgar é a intensidade de massa [10], definida como a razão entre a massa total de materiais usados num processo (reagentes, solventes, outros materiais auxiliares, etc.) e a massa de produto obtido. Trata-se de uma grandeza adimensional, tal como o Factor $E$, mas é expressa vulgarmente em $\mathrm{kg} / \mathrm{kg}$.

Na situação ideal de não se produzirem coprodutos nem serem necessários reagentes auxiliares, e admitindo rendimento de $100 \%$, todos os materiais reagentes seriam incorporados no produto desejado, e a intensidade de massa teria um valor ideal igual a um, mas na prática é sempre superior. Pode-se calcular um valor teórico da intensidade de massa a partir da lista de quantidades (massas) da totalidade de reagentes (estequiométricos, auxiliares, solventes, etc.), admitindo que os rendimentos são de $100 \%$, e obtendo a massa de produto (teórica) pela estequiometria das reacções (equações estequiométricas). No entanto, este valor teórico é inferior ao valor real, porque os rendimentos não atingem $100 \%$, é frequentemente difícil contabilizar todos os reagentes auxiliares, etc.

Comparação das métricas. Na Fig. 5 contrasta-se as definições das duas métricas usadas para a avaliação da extensão em que são produzidos resíduos. A QV procura obter utilização máxima dos materiais - a chamada desmaterialização da produção. Para isso, prescreve o uso de processos com Factor $\mathrm{E}$ ou intensidade de massa tão baixos quanto for possível - estas são métricas inversas da verdura. que, em geral, limitam a exactidão dos valores obtidos; (ii) por via experimental, a partir de dados mais completos colhidos no laboratório, ou, mais fidedignamente, em instalações piloto, ou de valores históricos de parâmetros técnicos recolhidos ao longo da operação das instalações industriais - neste caso, frequentemente, os registos são escassos ou incompletos, o que limita as métricas que podem ser calculadas.

O cálculo de valores teóricos conduz a valores maiores que os experimentais para as métricas de incorporação de átomos no produto e menores para as métricas de resíduos, o que resulta de, nas situações reais, os dois tipos de métricas avaliarem aspectos diferentes do destino dos átomos. Estas diferenças resultam das hipóteses usadas no cálculo dos valores teóricos não serem válidas, por exemplo: (i) admitir rendimentos de $100 \%$; (ii) ignorar o uso de excesso de reagentes; e (iii) não considerar substâncias que não aparecem explicitamente nas equações químicas e nas listas de reagentes auxiliares e, por isso, não são contabilizados, mas que dão origem a resíduos adicionais (por

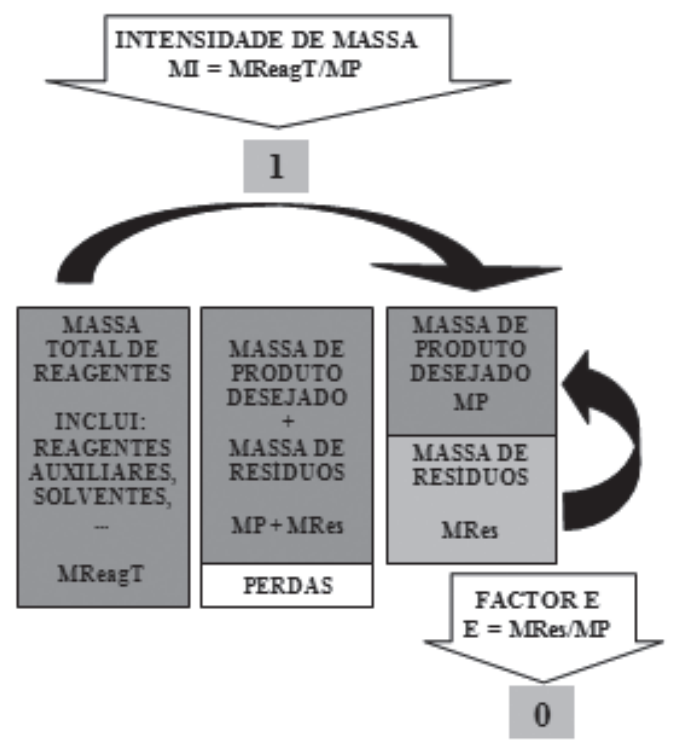

Figura 5 Comparação do Factor E com a intensidade de massa (MI). Ver legenda da figura anterior Como o que está em jogo é a avaliação da produção de resíduos, a massa total de reagentes inclui reagentes auxiliares, solventes, etc. (comparar com a Fig. 4)

\section{Cálculos de métricas de massa}

As métricas de massa podem ser obtidas por cálculos de dois tipos: (i) por via teórica, por cálculos estequiométricos a partir das equações químicas, admitindo hipóteses simplificativas - exemplo, catalisadores), etc.

Os valores reais das métricas dependem ainda de outros factores como, por exemplo, a extensão da reciclagem de reagentes não transformados, de recuperação de solventes, 
etc. A nível dos processos industriais, só são obtidos valores reais fidedignos se se dispuser de balanços materiais suficientemente completos, o que nem sempre sucede.

Os valores teóricos da economia atómica são muito fáceis de calcular e úteis para a introdução da QV com suporte quantitativo $[11,12]$. Os cálculos têm um nível de dificuldade semelhante ao do rendimento, sendo adequados para abordagens elementares. O cálculo de valores reais com base em dados experimentais pode ser realizado com dados de laboratório [13] para ilustrar o aumento de complexidade de cálculo para situações reais.

Para valores teóricos existem relações entre as métricas referentes a reacções simples traduzidas por uma única equação estequiométrica, que são simples e facilmente dedutíveis (ver Quadro 2). Nomeadamente, se se desprezarem perdas de massa no processo, para valores elevados do Factor $\mathrm{E}$, este é igual à intensidade de massa e ao inverso da utilização atómica; no caso ideal de não serem necessários reagentes auxiliares, solventes, etc., a economia atómica e a intensidade de massa são o inverso uma da outra.

Como o estabelecimento destas relações exige hipóteses simplistas, elas não têm grande significado químico nem interesse prático, mas a sua existência mostra que as métricas apresentadas não são independentes - aferem todas uma grandeza mais fundamental, a produtividade atómica.

Quadro 2 Relações entre os valores teóricos das métricas de massa para uma reacção simples

Economia atómica (AE) e a
intensidade de massa (MI) $\mathrm{AE}=1 / \mathrm{MI}$

Factor $\mathrm{E}$ e intensidade de massa (MI) $\mathrm{MI}=(\mathrm{MP}+\mathrm{MRes}) / \mathrm{MP}=1+\mathrm{E}$ Se $\mathrm{E}>>1, \mathrm{MI} \approx \mathrm{E}$

Factor E e utilização atómica (AU) $(1 / A U)=(M P+M R e s) / M P=1+E$ Se $E>>1, A U=1 /(1+E) \approx 1 / E$

\section{ConcLusões}

A necessidade cada vez mais premente de inventar vias de síntese mais verdes que as tradicionais, e de as escalar por desenvolvimento verde de processo para se chegar a processos industriais mais eficientes e benignos para o ambiente que os vigentes, arrasta consigo a necessidade de avaliar quantitativamente a verdura das reacções, vias de síntese, processos químico-industriais, etc., para hierarquizar as alternativas disponíveis em cada caso e facilitar a escolha das mais apropriadas para se caminhar para a Sustentabilidade - neste contexto, para obter comparações tanto quanto possível fidedignas, procura-se estabelecer métricas de verdura apropriadas. No entanto, dada a diversidade de situações a aferir, esta tarefa não é fácil e exige uma variedade de métricas dirigidas a diferentes tipos de variáveis [14,15].

A QV exige mais métricas de massa destinadas a aferir a qualidade da manipulação dos átomos que as clássicas (rendimento e selectividade), para guiar a execução das reacções de síntese no sentido da minimização de resíduos e do aumento da incorporação dos átomos no produto. Fundamentalmente, as quatro métricas de verdura discutidas avaliam uma mesma característica fundamental da reacção, a produtividade atómica, embora de dois pontos de vista diferentes - por um lado, a extensão em que é conseguida a colocação dos átomos disponíveis no produto desejado e, por outro, o seu não desperdício em resíduos.

$\mathrm{Na}$ prática real da química é vulgar não se dispor de dados completos sobre resíduos e as métricas que se podem calcular variam de caso para caso. Nos casos em que é possível calcular mais do que uma, é frequente obter-se valores discrepantes, devido a incertezas nos dados, hipóteses simplificativas ou estimativas impostas pela incompletude destes, etc. [15]. Por outro lado, como a QV é recente e os conceitos estão ainda em construção, não houve oportunidade para uma sistematização eficaz dos métricas - por isso, a literatura é, por vezes, confusa e inclui métricas alternativas para um mesmo fim e várias designações para uma mesma métrica. Os químicos industriais têm vindo a experimentar e usar uma variedade de métricas para aferir a verdura $[10,14,15]$, obtidas e manejadas em regime exploratório e que presentemente continuam a ser sujeitas a investigação. Esta visa, por exemplo, avaliar a fidedignidade das métricas e a sua sensibilidade à alteração de condições (robustez), aferi-las mutuamente por comparação, adquirir prática da sua utilização em condições industriais reais, etc. - com vista à sua progressiva revisão para aperfeiçoamento, até se atingir, eventualmente, um conjunto que possa ser convencionado como padrão. Em suma, o estudo das métricas da QV está longe de estar completo e constitui presentemente um campo de investigação activo (por exemplo, quanto a métricas para uso laboratorial, ver $[16,17])$.

\section{Notas}

1 Originariamente, os termos métrica e metrificação, e os conceitos a eles subjacentes, eram usados apenas em poesia e música. Posteriormente, foram adoptados para designar actividades de caracterização de sistemas dinâmicos complexos. Neste contexto, chama-se métrica a um sistema de avaliação quantitativa do funcionamento de um sistema que permita sentir e avaliar o modo como ele funciona - os seus resultados informam sobre as características e estado de evolução do sistema e servem de base, por exemplo, para tomar decisões sobre as alterações a realizar no respectivo controlo para corrigir o percurso e cumprir o objectivo pretendido. A metrificação de um sistema envolve, em geral, várias grandezas, ou razões de duas grandezas, ou funções de várias grandezas (por exemplo, métricas globais), ou índices adimensionais. As métricas devem ser: (i) simples e intuitivas, para permitir uma compreensão imediata e fáci do modo como o sistema funciona; (ii) em número tão pequeno quanto possível, para não requererem trabalho desnecessário; (iii) fáceis de obter, por medição directa ou, preferivelmente, por cálculo simples a partir de dados já disponíveis; (iv) robustas, para não sentir os efeitos de pequenas flutuações no sistema devidas ao acaso; e (v) não devem ser perversas - não induzir em erro o utilizador, de tal modo que este reaja sobre o sistema modificando a sua evolução no sentido contrário ao desejado, provocando uma mudança incontrolável, 
etc. As métricas não constituem uma descrição rigorosa do sistema, fornecem apenas informação indicativa do seu estado e modo de funcionamento. No entanto, como o conhecimento dos sistemas complexos envolve, em geral, incertezas elevadas (princípio da incerteza geral), o seu uso é muito útil para se avaliar e manejar tais sistemas. Por outro lado, as métricas proporcionam informação com alcance mais amplo do que aquilo que efectivamente medem - incluindo informação para avaliar a globalidade do sistema. A sua determinação repetitiva ao longo do tempo pode evidenciar tendências de evolução, ou fenómenos em emersão no sistema, que de outra forma passariam despercebidos; são também muito úteis na avaliação comparativa de sistemas alternativos com vista a optar por aquele que melhor permite cumprir o objectivo requerido. Como em Química Industrial a realização de reacções químicas envolve sistemas dinâmicos e estes são frequentemente complexos, o uso de métricas no seu controlo é importante e vulgar - embora sem esta designação.

2 Nos processos contínuos, em que o reactor (reactor de fluxo) é alimentado continuamente com reagentes e se retira continuamente produto, reciclando-se frequentemente reagentes não transformados, a métrica do rendimento é mais elaborada. Neste caso, a metrificação envolve duas grandezas, o rendimento global do processo - comparação das quantidades saídas para fora da instalação global com as entradas de fora - e o rendimento por passagem no reactor - comparação das quantidades saídas do reactor com as entradas no mesmo, que incluem as recicladas e as de fora. Os processos contínuos são, em geral, os usados na Química Industrial Pesada, para obter os produtos químicos preparados em grandes tonelagens.

${ }^{3}$ Os coprodutos são compostos não desejados obtidos em paralelo com o produto principal, que podem ser de dois tipos: resíduos ou subprodutos. Os subprodutos são os compostos que encontram aplicação noutro processo, sendo, portanto, vendáveis ou utilizáveis; os resíduos não são aproveitáveis e têm de ser depostos no ambiente, podendo exigir tratamento prévio para os tornar inócuos. A diferença entre resíduo e subproduto pode ser ténue: por exemplo, um coproduto pode encontrar aplicação numa dada instalação industrial ou num dado local, por servir para a preparação de outro composto, sendo aí um subproduto; mas, noutro local em que este outro composto não seja fabricado, constituirá um resíduo. No entanto, seguindo o critério definido acima, se se encontrar um modo de utilização para ele, o resíduo "é promovido" a subproduto! Por isso, frequentemente, os termos coproduto e resíduo são usados como sinónimos. A Ecologia Industrial tem como objectivo montar uma nova Indústria Química em que se maximize o aproveitamento de resíduos como reagentes para fechar os ciclos de materiais na tecnosfera.

${ }^{4}$ Os resíduos podem ser de tipos variados - coprodutos não desejados, reagentes em excesso que não foram transformados, reagentes auxiliares, nomeadamente solventes (mas não só), etc. - mas acarretam sempre desperdício de átomos.

${ }^{5}$ Note-se, embora seja secundário na análise das métricas de massa, que a força motriz que levou a esta descoberta foi o conjunto de problemas ambientais que os resíduos provocam: necessidade de deposição no ambiente (com precauções especiais quando são perigosos), tratamento prévio quando são tóxicos, etc. - todas estas operações (e não só) implicam acréscimo de custos e, por isso, um esforço intencional de minimização de resíduos no desenvolvimento dos processos industriais para o fabrico de produtos químicos tem sempre benefícios económicos, em muitos casos importantes.

6 A produtividade dos materiais sempre foi importante em termos económicos mas é cada vez mais importante à medida que a delapidação dos recursos naturais não renováveis avança e aumenta a sua escassez. A Ecologia Industrial procura implementar genericamente a desmaterialização - uma forma de aumentar a produtividade dos materiais - pelo que a sua prática é muito importante em Química Industrial Verde.

${ }^{7}$ Embora seja possível exprimir a utilização atómica e a economia atómica em termos de quantidades de substâncias (por exemplo, para a economia atómica: razão de número de moles de átomos nos reagentes incorporados no produto e o número total de moles de átomos nos reagentes) não é costume fazê-lo, pois estas métricas seriam menos discriminatórias - mostram diferenças menores quando usadas para comparar reacções ou processos.

\section{REFERÊNCIAS}

[1] A. A. S. C. Machado, "Química e Desenvolvimento Sustentável - QV, QUIVES, QUISUS?", Química - Bol. S. P. Q. 95 (2004) 59-67.

[2] P. T. Anastas e J. C. Warner, Green Chemistry - Theory and Practice, Oxford UP, Oxford, 1998.
[3] A. Steinbach e R. Winkenbach, "Choose Products for their Productivity", Chem. Eng., Abril (2000) 94-104.

[4] R. A. Frosch (ed.), Industrial Environmental Performance Metrics - Challenges and Opportunities, National Academy Press, Washington, 1999.

[5] D. T. Allen e D. R. Shonnard, Green Engineering - Environmentally Conscious Design of Chemical Processes, Prentice-Hall, Upper Saddle River, 2002.

[6] A. A. S. C. Machado, "O Quadro de Classificação Periódica da Sustentabilidade - Uma Metáfora para a QV e a Ecologia Industrial", Química - Bol. S. P. Q. 98 (2005) 21-28.

[7] B. M. Trost, "The Atom Economy - A Search for Synthetic Efficiency", Science 254 (1991) 1471-1477.

[8] R.A. Sheldon, "Organic Synthesis Past, Present and Future", Chem. Ind (London) (1992) 903-906.

[9] R. A. Sheldon," Consider the Environmental Quotient", ChemTech 24(3) (1994) 39-47.

[10] A. D. Curzons, D. J. C. Constable e D. N. Mortimer, "So You Think your Process is Green, How do You Know?", Green Chem. 3 (2001) 1-6.

[11] M. Lancaster, Green Chemistry - An Introductory Text, RSC, Londres, 2002, p. 13-15.

[12] M. C. Cann e M. E. Connelly, RealWorld Cases in Green Chemistry, ACS, 2000 , p. 5-12.

[13] K. M. Doxsee e J. E. Hutchison, Green Organic Chemistry - Strategies, Tools and Laboratory Experiments, Thomson, 2004, p. 91-92.

[14] A. D. Curzons, D. J. C. Constable et. al., "Green Chemistry Measures for Process Research and Development", Green Chem. 3 (2001) 7-9.

[15] D. J. C. Constable, A. D. Curzons e V. L. Cunningham, "Metrics to Green Chemistry - Which are the Best?", Green Chem. 4 (2002) 521-527.

[16] K. van Anken, L. Strekowski e L. Patiny, "EcoScale - A Semiquantitative Tool to Select an Organic Preparation Based on Economical and Ecological Parameters", Beilstein J. Org. Chem. 2 (2006) 3-9.

[17] M. Eissen, R. Mazur, H. G. Quebbemann e K. H. Pennemann, "Atom Economy and Yield of Synthesis Sequences", Helv. Chim. Acta 87 (2004) 524-535. 
A successful concept

The national

chemical societies

of nine European

countries are

co-owners of

ChemPhysChem
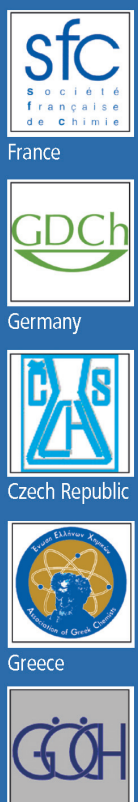

क्षेण

Austria
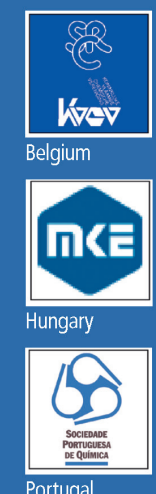

Subscribe now!

For further information and to subscribe please send an E-mail to:

subinfo@wiley.com

(USA/Canada)

service@wiley-vch.de

(Germany/Austria/Switzerland)

cs-journals@wiley.co.uk

(all other areas)

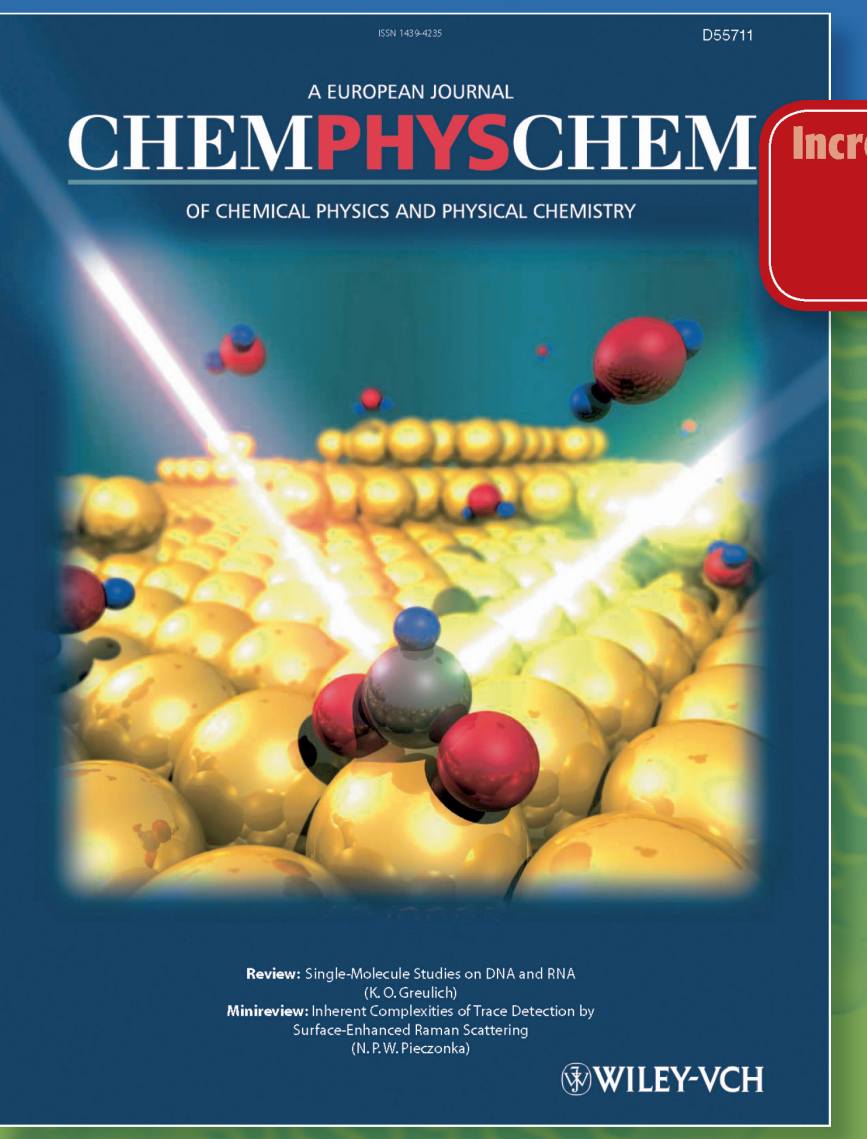

ChemPhysChem a premier journal for physical chemistry and chemical physics covering

Solid-State and Soft-Matter Research

Chairmen of the

Electro- and Photochemistry

Editorial Advisory Board:

Femtochemistry and Nanotechnology

Frans.C. De Schryver (Belgium)

Complex Systems

Single-Molecule Research James T. Hynes (France, USA)

Clusters and Colloids

- Catalysis and Surface Science

- Biophysics and Physical Biochemistry

\section{Editor:}

Peter Gölitz

Deputy Editor:

- Atmospheric and Environmental Chemistry

and many more topics

\section{Visit ChemPhyschem online} wur.chemphyschem.or:

Interscien
discover something great

(WILEY-VCH 